\title{
Predation vulnerability of planktonic copepods: consequences of predator foraging strategies and prey sensory abilities
}

\author{
Markku Viitasalo ${ }^{1, *}$, Thomas Kiørboe $^{2}$, Juha Flinkman $^{1,3}$, Lars W. Pedersen ${ }^{2}$, \\ André W. Visser ${ }^{2}$ \\ 'Tvärminne Zoological Station and Department of Ecology and Systematics, Division of Hydrobiology, PO Box 17. \\ FIN-00014 University of Helsinki, Finland \\ ${ }^{2}$ Danish Institute for Fisheries Research, Kavalérgården 6, DK-2920 Charlottenlund, Denmark \\ ${ }^{3}$ Finnish Institute of Marine Research, PO Box 33, FIN-00931 Helsinki, Finland
}

\begin{abstract}
We investigated the vulnerability of 2 copepod species (Eurytemora affinis and Temora longicornis) to predation by predators with different foraging modes, three-spined stickleback Gasterosteus aculeatus juveniles and mysid shrimps Neomysis integer. Copepods were videofilmed escaping from predators and from an artificial flow field, and the results were used in a model of hydrodynamic disturbance generated by a predator The copepods detected mysids from a significantly larger distance than they detected sticklebacks $(0.45$ and $0.24 \mathrm{~cm}$, respectively). Consequently, the capture success of the sticklebacks was higher than that of mysids. In the case of sticklebacks foraging on $E$. affinis, copepod reaction distance was significantly correlated with stickleback approaching speed; sticklebacks captured a copepod only if they were able to slowly approach to within a strike distance of $<0.1 \mathrm{~cm}$ from the prey. Also, there was a major difference between the vulnerabilities of the 2 prey species: the capture success of sticklebacks was $92 \%$ with $T$. longicornis and $53 \%$ with E. affinis. This corresponded with experiments with artificial flow, where the threshold fluid velocity gradient eliciting an escape response in copepods was 4 times higher in $T$. longicornis than in E. affinis $\left(8.2\right.$ and $2.1 \mathrm{~s}^{-1}$, respectively). The hydrodynamic model accurately predicted the positive relationship between stickleback approaching speed and copepod reaction distance, as well as the difference between the 2 copepod species. This suggests that, by using simple artificial flow experiments, we can rank various zooplankton species according to their escape capabilities, and thus predict their vulnerability to predation by small fish with different motility patterns. In contrast, the model did not conform with observations on mysids. Apparently, the hydrodynamic disturbance created by a mysid is not related to its swimming speed, but to some other factor, such as the beat rate of swimming appendages.
\end{abstract}

KEY WORDS: Predation vulnerability - Escape response Hydrodynamic signals - Prey selection Eurytemora affinis . Temora longicornis . Gasterosteus aculeatus - Neomysis integer

\section{INTRODUCTION}

The vulnerability of a planktonic prey to predation can be measured as the product of the encounter rate with predator and the escape success of the prey (Pas-

\footnotetext{
-Address for correspondence: Department of Ecology and Systematics, Division of Hydrobiology, PO Box 17, FIN00014 University of Helsinki, Finland.

E-mail: markku.viitasalo@helsinki.fi
}

torok 1981, Greene 1986). The encounter rate is directly proportional to the velocity difference between predator and prey (Gerritsen \& Strickler 1977. Tiselius et al. 1993) as well as prey characteristics that affect the predator's reactive distance, such as prey size (Brooks \& Dodson 1965, Gardner 1981, Flinkman et al. 1992), colour contrast (Zaret 1972, Zaret \& Kerfoot 1975, Buskey 1994) and behaviour (O'Brien et al. 1976, Williamson 1980, Zaret 1980, Yen \& Strickler 1996). The escape success, in contrast, depends on the 
perceptive ability of the prey and its behavioural and morphological defences.

Both planktonic predators and prey can be classified into functional groups according to their swimming and feeding behaviour. These behaviours significantly influence the outcome of the predatory interaction, through their effect on encounter rates and prey escape capabilities. For instance, predators may search for prey by 'cruising' or 'ambushing'. Cruising predators locate prey by fast swimming, while predators that ambush mainly rely on prey movement (or water motion) in encountering prey. Because many planktonic prey species use mechanosensing in detecting predators (e.g Strickler \& Bal 1973, Strickler 1975), and because cruising creates a larger hydrodynamic signal than ambushing, there is a trade-off between optimisation of encounter rates and maximisation of capture success. Predators therefore often use intermediate stop-and-go search patterns $\left(\mathrm{O}^{\prime} \mathrm{Brien}\right.$ et al. $1989,1990)$ and vary their swimming behaviour according to prey availability (Coughlin et al. 1992). Also, the perceptive ability of prey is intimately linked to their behavioural ecology. In particular, copepods have mechanosensing hairs and setae on their body and antenna, which are especially conspicuous in species that hunt for motile prey, such as ciliates or copepod nauplii (Fleminger 1973, Strickler \& Bal 1973, Strickler 1975, Yen et al. 1992). It is therefore possible that predatory copepods are better able to detect hydrodynamic disturbance created by their own predators than predominantly suspension feeding copepods.

The escape performance of different zooplankton taxa has been investigated by subjecting the experimental animals to flow fields created by pipettes or moving obstacles (e.g. Szlauer 1964, 1965, Singarajah 1969, 1975, Janssen 1976, Drenner et al. 1978, Landry 1.978, Drenner \& McComas 1980). Later videographic studies have also quantified the flow fields around predators and prey. However, most of the detailed videographic studies have experimented with artificial (Haury et al. 1980, Gilbert \& Kirk 1988, Kirk \& Gilbert 1988, Buskey 1994, Fields \& Yen 1996) or tethered predators (Drost 1987, Yen \& Fields 1992) and with small rotifer and cladoceran prey that possess limited escape capabilities. In studies where interactions between larger zooplankton and free-swimming predators have been analysed in detail (e.g. Drost 1987, Drost et al. 1988, Kils 1992), the spatial scales and the viewpoint of the study have essentially been those of the predator.

We investigated the escape and sensory capabilities of 2 copepod species, Eurytemora affinis and Temora longicornis, when preyed upon by 2 different predators, three-spined stickleback Gasterosteus aculeatus juveniles and mysid shrimps Neomysis integer. These 4 experimental species represent different functional predator and prey groups: three-spined sticklebacks are visual predators that search for prey in a stop-andgo fashion (Beukema 1968), whereas mysid shrimps are usually held non-visual cruisers that prey on small prey by creating a feeding current and on larger prey by raptorial feeding (Cooper \& Goldman 1980, Mauchline 1980. Siegfried \& Kopache 1980, Grossnickle 1982). There is a major difference in the swimming modes of the predators as well: sticklebacks mainly swim by thrusts of the tail, whereas mysids propel themselves forward by paddling with their thoracic appendages. This probably makes the hydrodynamic disturbance produced by mysids and sticklebacks very different. Our objectives were to compare the susceptibilities of the 2 copepod species to predation by these predator types, and to determine how well simple hydrodynamic laws explain the observed responses. This was accomplished by videofilming copepods escaping from the predators and from an artificial flow field, and by combining the information into a simple model of hydrodynamic disturbance generated by a predator.

\section{MATERIALS AND METHODS}

Experimental organisms and sampling. Eurytemora affinis (Poppe) and Temora longicornis (Müler) are common calanoid copepod species in the Baltic Sea. Both species are as adults $\sim 1 \mathrm{~mm}$ long; $E$. affinis females carry the eggs in an egg sac, while $T$. longicornis sheds its eggs freely in the water. In the Baltic Sea, both species are important prey for various planktivores, such as clupeids (Sandström 1980. Flinkman et al. 1992, 1998), sticklebacks (Hangelin \& Vuorinen 1988, Leinikki 1995) and mysid shrimps (Mysis spp.) (Hansson et al. 1990, Rudstam et al. 1992, Mohammadian et al. 1997, Viitasalo \& Rautio 1998). Three-spined sticklebacks Gasterosteus aculeatus L. occur both in the sublittoral and in the open sea, and feed mainly on crustacean zoopiankton (Beukema 1968, Rajasilta 1980, Thorman \& Wiederholm 1986, Leinikki 1995). Neomysis integer (Leach) usually dwells in relatively shallow water and feeds on a large variety of planktonic and benthic food items, including copepods (Irvine et al. 1993, Uitto et al. 1995, Nordström 1997).

The experimental animals were collected in August 1996 ('predator experiments') and in August 1997 ('experiments with artificial flow') in the archipelago of Hanko Peninsula, SW Finland. The copepods were collected with a Hensen plankton net (mesh size $100 \mu \mathrm{m}$ ), from 0 to $20 \mathrm{~m}$ depth. The sample was poured into a cool box with $15 \mathrm{l}$ of seawater from ca 0,20 and $30 \mathrm{~m}$ 
depth (5 l from each depth). The cool box was quickly taken to a temperature controlled room $\left(15^{\circ} \mathrm{C}\right.$ in 1996 and $13^{\circ} \mathrm{C}$ in 1997 ), and the water was aerated. Copepods were picked from the sample and placed into 11 glass jars with filtered seawater with aeration. Predators were collected the same day from a nearby sublittoral area by using small nets and an epibenthic sledge-sampler The fish and mysids were taken into the laboratory, measured and placed in $2 \mathrm{l}$ glass jars containing filtered seawater. Aeration was begun and the animals were left to acclimate to laboratory conditions for ca $2 \mathrm{~d}$.

Filming equipment. The animals were filmed in 11 cubic Plexiglas aquaria. Illumination for the cameras was provided by infrared light emitting diodes (LEDs). To enable measurements of distances and velocities in 3 dimensions, 2 video cameras (Mintron MTV-1802CD equipped with $35 \mathrm{~mm}$ Nikkor lenses) were fixed at right angles at $90 \mathrm{~cm}$ distance from the aquarium. The 2 images were combined onto 1 monitor with an image mixer, and recorded with a Panasonic VCR (resolution 50 frames $\mathrm{s}^{-1}$ ). Time in $1 / 100 \mathrm{~s}$ was displayed on the monitor with a video timer. In the predator experiments the area seen on the monitor was $8 \mathrm{~cm}$ wide and $8 \mathrm{~cm}$ high, and the depth of field covered the whole aquarium; in the experiments with artificial flow, the view was $4 \mathrm{~cm}$ wide and $6 \mathrm{~cm}$ high. A third camera (with a $105 \mathrm{~mm}$ macro lens) was placed on a tripod to obtain 2-dimensional close-up views. The magnification in the closeups varied according to position of the objects in the aquaria and turning and moving of the tripod. We hereafter refer to films made with the 2 cameras and at low magnification as '3-D films', while the films made with 1 camera and at high magnification are called 'close-up films'.

Predator experiments. The experiments with sticklebacks were made in room light, whereas the experiments with mysids were performed in darkness (except for the infrared LEDs). However, when making the close-up films, the monitor was on, which created a low light in the room.

In the first experiment (Expt 1), 3 Neomysis integer (each $1.0 \mathrm{~cm}$ in length) were placed in an aquarium with 40- $\mu \mathrm{m}$-filtered seawater and 80 egg-carrying Eurytemora affinis females, and the interactions were filmed at high and low magnifications. In the second experiment (Expt 2A), 3 stickleback juveniles (lengths 1.5, 1.7 and $1.8 \mathrm{~cm}$ ) were placed in an aquarium with $40-\mu \mathrm{m}$-filtered seawater and 130 egg-carrying E. affinis females. The fish ate the prey rapidly, so $\sim 200$ additional copepods were picked and given to the fish (Expt 2B).

Experiments with Temora longicornis were made the next day (Expt 3). First, 70 adult T. longicornis females were transferred into the aquarium with the same Neomysis integer as in Expt 1 (which had been kept overnight in the aquarium without food). Second, $T$. longicornis were filmed with sticklebacks. Because $N$. integer managed to capture only very few prey, the $T$. longicornis from the Expt 3 were given to the sticklebacks from the Expt 2 (which had been kept in a 2 l glass jar without food overnight) (Expt $4 \mathrm{~A}$ ). As the fish again rapidly depleted the prey, 100 new $T$. longicornis were picked and given to the sticklebacks (Expt 4B).

Experiments with artificial flow. The experiments with artificial flow were conducted in dim room light, in similar $1 \mathrm{I}$ aquaria as in the predator experiments. A Pasteur pipette was fixed vertically (from above) into the middle of the aquarium and connected to a thin silicon tube with its free end hanging below the aquarium; this created a water flow to which the copepods reacted. To be able to quantify the flow field, a small amount of cultured phytoplankton was added into the aquarium. Then, 100 Eurytemora affinis were added and the escape reactions were filmed as above. When the water level was close to the tip of the pipette, more water was added, and filming was continued until a sufficient number of escapes and captures were observed. The same procedure was repeated with 100 Temora longicornis. With this set-up, the hydraulic head height increased by $\sim 10 \%$ during each fill, but, since flow in the outlet tube was turbulent, volume flow scales with the square-root of the head height. Thus, the volume flow varied by only $\sim 5 \%$ during each fill. We restricted our analysis to the region in front of (i.e. below) the pipette.

Analyses of video films. Time and distance measurements of the predatory interactions were made with an image analysing program. We defined an 'interaction' as starting when a predator detected a prey (or when a prey detected a predator) and ending when the predator captured or lost the prey. One interaction may thus contain several escapes, attacks and pursuits. In the case of sticklebacks, prey detection was distinguished from a sharp turn by which the fish oriented towards the prey. The interactions with mysids were identified from a combination of a copepod escape response and a sharp movement by the mysid. Each interaction was analysed frame by frame. Positions of the prey and the nose or rostrum of the predator were marked on the 2 perpendicular views, which resulted in $x-y-z$ and time coordinates. From these records we calculated prey location and attack distances of predators, reaction distances of copepods to predators, as well as velocities for fish, mysids and copepods during various sequences of the interactions (Table 1). All interactions that took place closer than $-1 \mathrm{~cm}$ from aquarium walls were excluded from the analysis. The foraging success of fish and mysids was assessed from the 3-D films as the fraction of interactions ending with capture. The 
Table 1. Terms used in the text and parameters recorded from the films

\begin{tabular}{|c|c|}
\hline Variable & Definition \\
\hline Interaction & $\begin{array}{l}\text { Encounter between a predator and a prey that starts with location of the prey and ends with prey } \\
\text { being captured or escaping outside the visual or sensory field of the predator. One interaction } \\
\text { may contain several attacks, escapes and pursuits }\end{array}$ \\
\hline \multicolumn{2}{|l|}{ Predator } \\
\hline Prey detection distance & $\begin{array}{l}\text { Distance from which the predator detects the prey. For example, a stickleback sharply turns } \\
\text { towards a copepod and initiates approach or a mysid clearly reacts to a copepod }\end{array}$ \\
\hline Approach & $\begin{array}{l}\text { For sticklebacks, the sequence between detecting the prey and initiating attack; for mysids, the } \\
\text { period when swimming towards the copepod }\end{array}$ \\
\hline Approach speed & $\begin{array}{l}\text { Speed during an approach in the case of sticklebacks, calculated for the period when the fish are } \\
\text { within } 0.5 \mathrm{~cm} \text { of the copepod; in the case of mysids, calculated for the last } \sim 0.4 \mathrm{~s} \text { of the approach }\end{array}$ \\
\hline Attack distance & $\begin{array}{l}\text { Distance between the nose/rostrum of the predator and the copepod at the beginning of the } \\
\text { attack }\end{array}$ \\
\hline Attack speed & Speed of the predator during the first $0.06 \mathrm{~s}$ of the attack \\
\hline Pursuit & $\begin{array}{l}\text { A sequence where the prey escapes but remains in the visual or sensory field of the predator, } \\
\text { which starts a new approach }\end{array}$ \\
\hline \multicolumn{2}{|r|}{ S } \\
\hline Reaction distance & Distance between the copepod and nose/rostrum of the predator at the beginning of escape \\
\hline Escape speed & Speed of the copepod during the first $0.06 \mathrm{~s}$ of the escape \\
\hline Total escape distance & Total distance travelled by the copepod during the escape, until it stopped completely \\
\hline Escape duration & Total duration of the escape, until it stopped completely \\
\hline
\end{tabular}

close-up films were mainly made to obtain qualitative information, but some measurements concerning mysid attack speeds were also made from them. This was done by measuring jump distances from the screen, and by scaling the measured distances with the mysid body length $(1 \mathrm{~cm})$.

In the experiments with artificial flow, the 3-dimensional flow field was quantified by analysing the velocities of 78 neutrally buoyant particles approaching the opening of the pipette (altogether 419 velocity-location data points). Copepod reaction distances from the mouth of the pipette were then measured. In cases where copepods performed several sequential escape jumps, only the first one was measured.

The hydrodynamic model. A predator moving through water generates velocity gradients in the ambient fluid, which copepods are believed to be able to perceive (Yen \& Fields 1992, Fields \& Yen 1996, Yen \& Strickler 1996). Copepods have hairs and setae on their body and antenna, and it is assumed that it is the bending of these setae that the copepods sense (Strickler \& Bal 1973, Gill 1985, Yen et al. 1992, Fields \& Yen 1996. 1997). Such bending may occur if there is a velocity difference between the copepod and the ambient fluid. The magnitude of the hydrodynamic signal potentially produced by the predator may, in the case of the approaching fish, be analysed by a simple model.

Following Tiselius \& Jonsson (1990), we can examine the velocity gradients generated by the fish by modelling the approaching fish as a translating sphere with a diameter equal to the diameter of the (front part) of the fish, and by assuming streamlines following creeping flow solutions (Berg 1993). This is a great simplification but may be warranted by the fact that, after having located the prey, the fish pushes itself forward by means of a thrust of the tail and approaches the prey front on. The radial and azimuthal components of the velocity of the fluid ( $v_{r}$ and $v_{\theta}$, respectively) relative to the sphere are (Berg 1993):

$$
\begin{aligned}
& v_{r}(r, \theta)=-U \cos \theta\left(1-\frac{3 a}{2 r}+\frac{a^{3}}{2 r^{3}}\right) \\
& v_{\theta}(r, \theta)=U \sin \theta\left(1-\frac{3 a}{4 r}-\frac{a^{3}}{4 r^{3}}\right)
\end{aligned}
$$

where $U$ is the velocity of the sphere, a the radius of the sphere, $r$ the radial distance from the centre of the sphere and $\theta$ the angle relative to the direction of motion of the sphere. The velocity gradients in this flow field can be decomposed into gradients along the streamlines and gradients perpendicular to the streamlines. The magnitude and distribution of these 2 components of the flow field are contoured in Fig. 1. In front of the approaching fish, velocity gradients along the streamlines (Fig. 1A) are at maximum and vary with the distance to the sphere, while the velocity gradients perpendicular to streamlines (Fig. 1B) are zero. For simplicity, and because the fish approaches the prey front on, we shall only consider fluid velocities directly in front of the sphere. At $\theta=0$, the fluid veloc- 

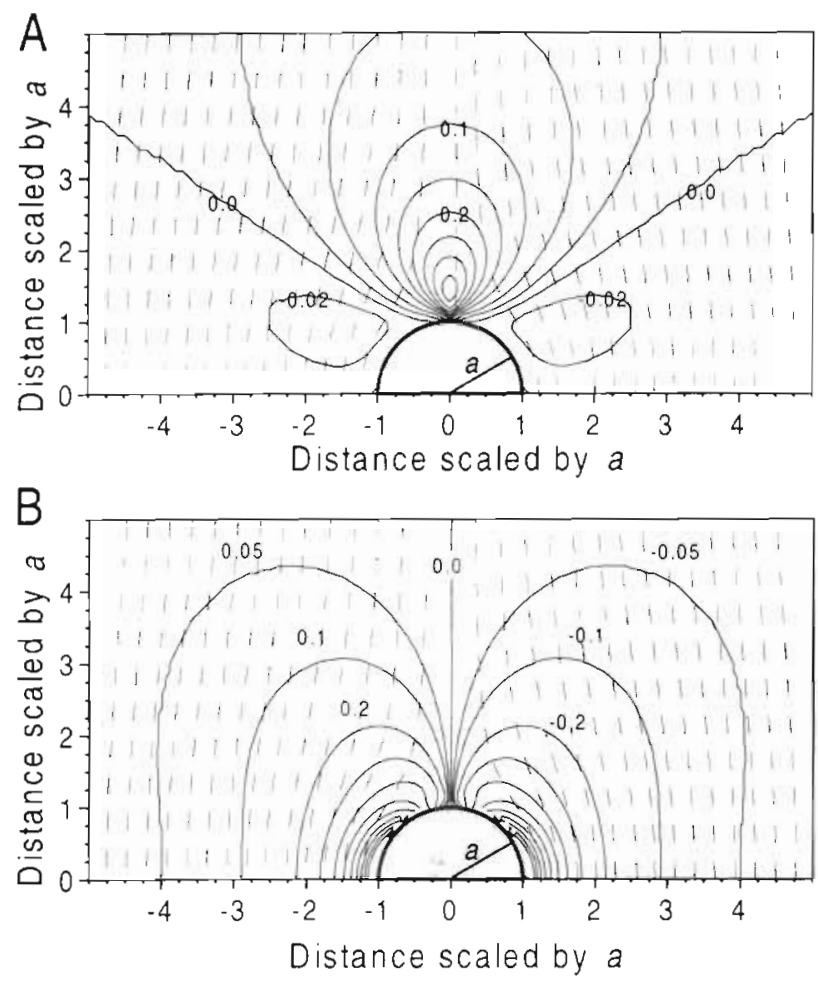

Fig. 1. Contour lines of the flow field produced by a translating sphere. The gradient in absolute velocity ( $\mathrm{A}$ ) in the alongstreamline direction and $(B)$ in the across-streamline direction. Streamlines are indicated by dashed lines. Velocity gradient units are scaled by U/a, where $U$ is the velocity of the sphere and $a$ is its radius

ity as a function of the distance to the sphere is given solely by Eq. (1), which thus simplifies to

$$
v(r)=-U\left(1-\frac{3 a}{2 r}+\frac{a^{3}}{2 r^{3}}\right)
$$

and the velocity gradient as a function of predator approach speed is

$$
\frac{\partial v}{\partial r}=\frac{3 U a}{2 r^{4}}\left(r^{2}-a^{2}\right)
$$

Assume now that the signal perceived by the copepod is directly proportional to the velocity gradient (as suggested below), and that there is a threshold velocity gradient, $\gamma^{*}$, that elicits an escape response in the copepod. By inserting this threshold gradient into the Eq. (4), the reaction distance, $R=r\left(\gamma^{*}\right)-a$, can be estimated as

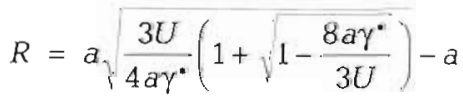

The dotted lines in Fig. 2 illustrate how the copepod reaction distance $R$ varies as a function of the approach velocity of the fish for $a=0.1 \mathrm{~cm}$ (the radius of the front

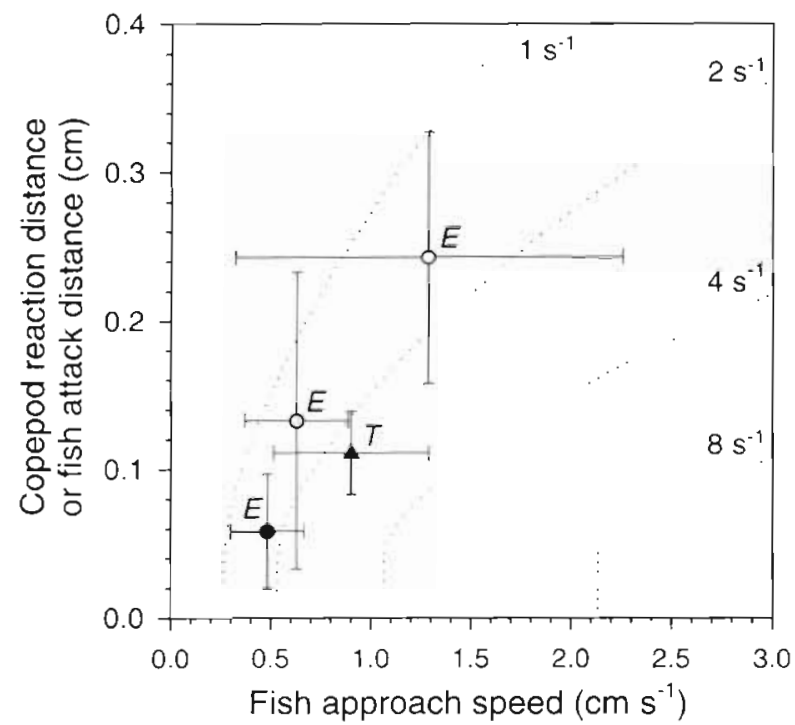

Fig. 2. Model of reaction distances of copepods as a function of predator (e.g. a stickleback with a nose radius, $a$, of $0.1 \mathrm{~cm}$ ) approach velocity. The 4 dotted isolines denote predicted reaction distances at arbitrary threshold velocity gradients $\left\{1,2,4\right.$ and $\left.8 \mathrm{~s}^{-1}\right\}$ at which copepods react to a simulated suction by a pipette. Symbols denote observations from the predator experiment (copepods escaping from sticklebacks; see 'Results'). (๑) Eurytemora affinis ( $E$ ) captures; (O) E. affinis escapes during attack; (O) E. affinis escapes before attack; (४) Temora longicornis $(T)$ captures. Vertical and horizontal bars denote SD

part of the fish). The 4 isolines, for arbitrary threshold velocity gradients of $1,2,4$ and $8 \mathrm{~s}^{-1}$, show that lower threshold velocity gradients (i.e. higher prey sensitivities) and higher predator approach speeds elicit escape responses at longer distances. None of the combinations of approach speed and distance between predator and prey that lie above each isoline will elicit an escape, whereas combinations below the line should not exist, since at the isoline the copepod escapes and thus increases its distance from the predator. For a complete description of the model and the theory behind it, refer to Kiørboe \& Visser (1999).

\section{RESULTS}

\section{Outcome of interactions in predator experiments}

We divided the predatory interactions between sticklebacks, mysids and the 2 copepod species into distinct components, i.e. search, prey detection, attack, capture/escape, and handling (Holling 1959, Gerritsen \& Strickler 1977, Kerfoot 1978). Fig. 3 gives an example of the events that took place from prey detection to capture or escape, during the 137 interactions recorded between sticklebacks and Eurytemora affi- 


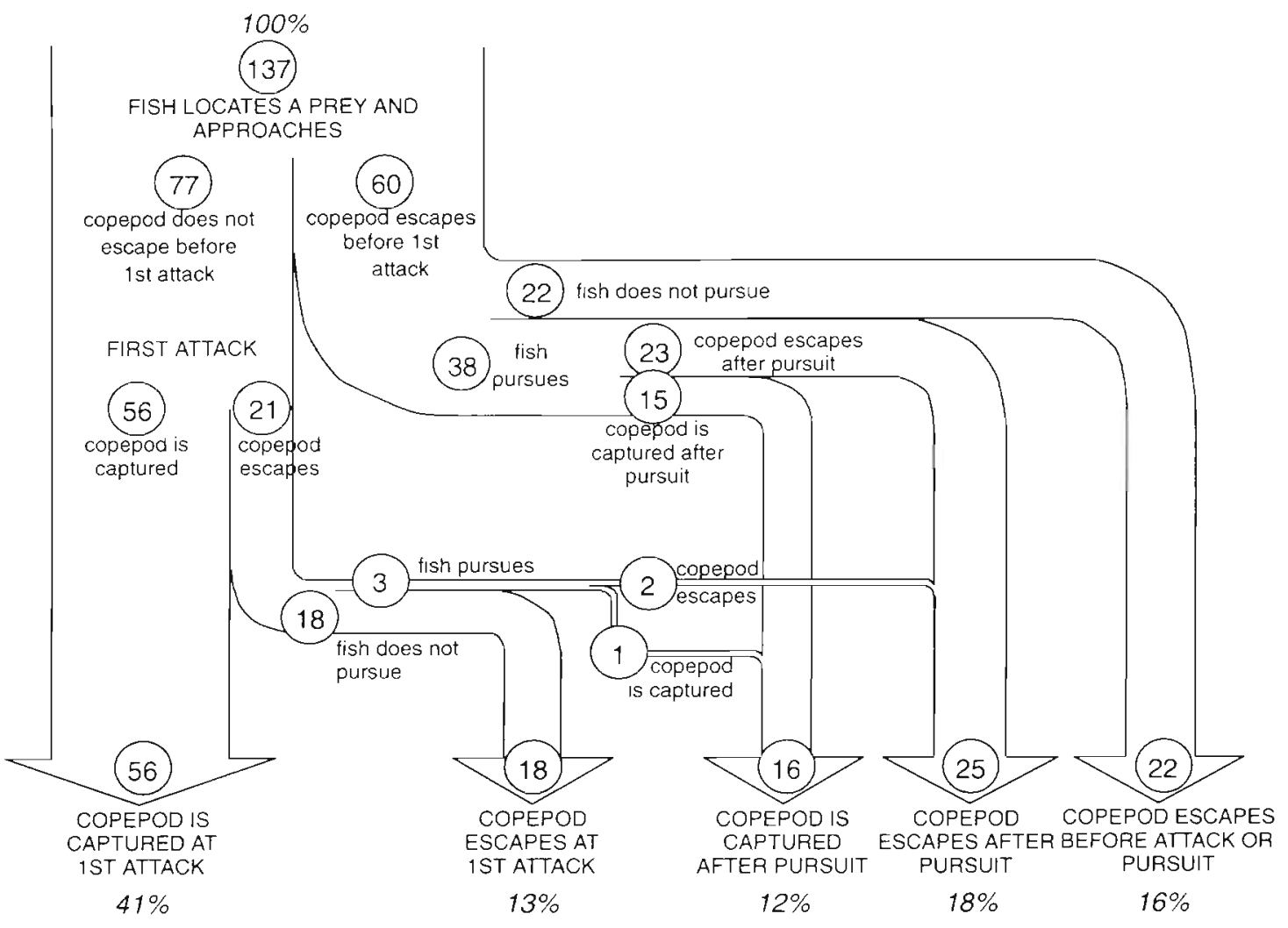

Fig. 3. Gasterosteus aculeatus vs Eurytemora affinis. Flow chart of the 137 predatory interactions in Expts $2 \mathrm{~A}$ and $2 \mathrm{~B}$. Encircled numbers refer to the absolute number of interactions of each type, percentages are given as percentages of the total number of interactions

nis. The most profitable strategy for sticklebacks was to approach to within a strike distance and attack before the copepod detected the predator. Sticklebacks captured E. affinis at first attack in $41 \%$ of the cases and captured prey after pursuit in $12 \%$ of cases

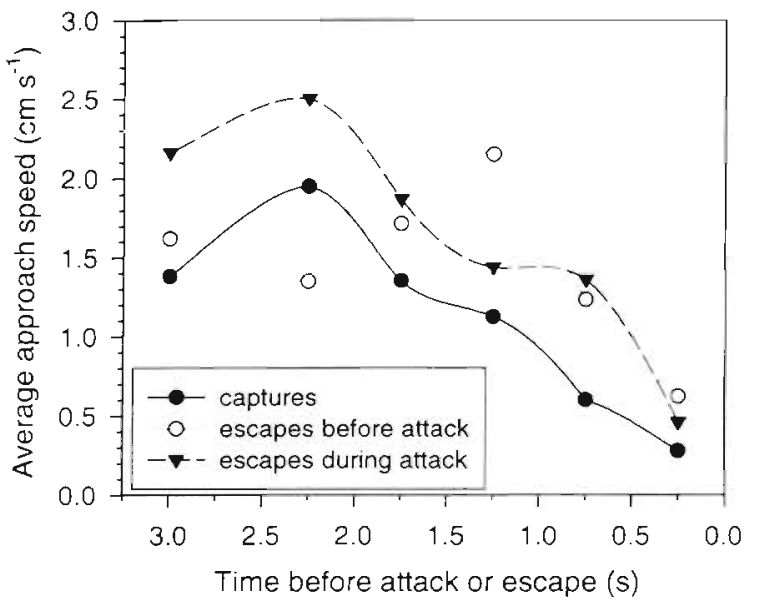

Fig. 4. Gasterosteus aculeatus vs Eurytemora affinss. Variations in the average approach speed of sticklebacks in cases where the prey was captured or escaped before or during the attack
(Fig. 3). The overall capture success of sticklebacks preying on E. affinis was thus $53 \%$. The capture success after pursuit was relatively poor: if the copepod escaped before the first attack, the fish followed in 38 cases out of 60 but captured the prey only in 15 cases.

With Temora longicornis, none of the stickleback attacks seen on 3-D films failed and only in 1 interaction out of 12 did the copepod escape before attack. The overall capture success of sticklebacks with $T$. longicornis was thus $92 \%$. In contrast, none of the Neomysis integer on the 3-D films succeeded in capturing either of the copepod species. However, we recorded d few captures on the close-up films (see below).

\section{Predator approach strategies}

When searching for a prey, the sticklebacks usually stayed in an almost fixed position, detecting prey from a mean distance of 2.06 to $2.25 \mathrm{~cm}$ (Table 2A). After locating a prey, the fish sharply accelerated but, when getting closer to the prey, it markedly slowed down (Fig. 4). The mean final approach speed of the fish (calculated for a range within $0.5 \mathrm{~cm}$ from the prey, which 

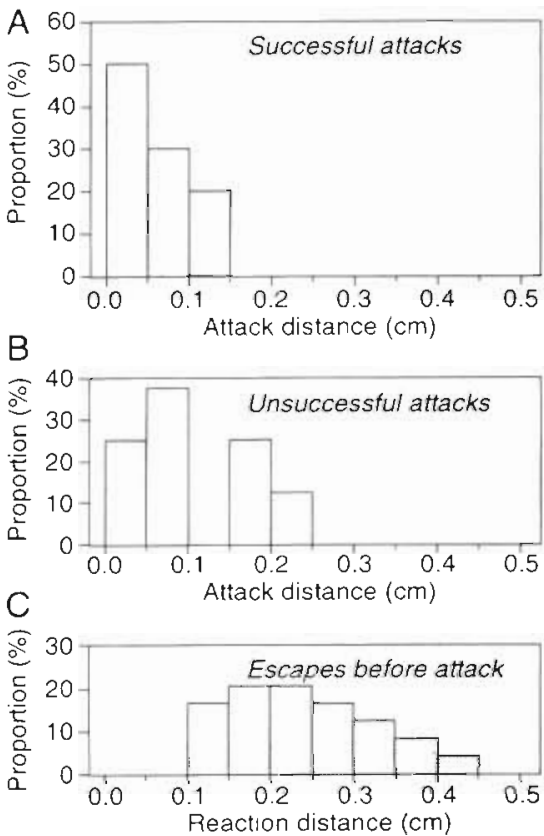

Fig. 6. Gasterosteus aculeatus vs Eurytemora affinis. Frequency distribution of fish attack distances (A) when prey was captured and (B) when prey escaped; (C) E. affinis reaction distances. Data from Expts $2 \mathrm{~A}$ and $2 \mathrm{~B}$

\section{Copepod escape behaviour}

Eurytemora affinis reacted to an approaching stickleback from a mean distance of $0.24 \mathrm{~cm}$ (Table 3A) (maximum $0.40 \mathrm{~cm}$ ). E. affinis were thus able to detect the fish 0.1 to $0.3 \mathrm{~cm}$ outside the potential attack range of the fish (cf. Fig. 6). The mean escape speed of $E$. affinis (8.58 $\mathrm{cm} \mathrm{s}^{-1}$; Table 3B) was twice as high as stickleback attack speed (cf. Table 2D). In contrast, the escape speed of Temora longicornis (mean $7.05 \mathrm{~cm} \mathrm{~s}^{-1}$; Table 3B) was not significantly higher than the attack speed of sticklebacks.

Táble 3. Predator experiment. (A) Copepods' reaction distances (in escapes before attack) and (B) escape speeds, with different predators (in escapes before or during attack). $\mathrm{n}=$ no. of observations

\begin{tabular}{|c|c|c|}
\hline \multirow[t]{2}{*}{ Variable/predator } & \multicolumn{2}{|c|}{ Copepod species } \\
\hline & $\begin{array}{c}\text { Eurytemora } \\
\text { affinis } \\
\text { Mean } \pm \mathrm{SD}(\mathrm{n})\end{array}$ & $\begin{array}{c}\text { Temora } \\
\text { longicornis } \\
\text { Mean } \pm \mathrm{SD}(\mathrm{n})\end{array}$ \\
\hline \multicolumn{3}{|c|}{ (A) Reaction distance $(\mathrm{cm})$} \\
\hline Stickleback & $0.24 \pm 0.08$ & $0.22(1)$ \\
\hline Mysid & $0.45 \pm 0.13(44)$ & $0.33 \pm 0.10(8)$ \\
\hline \multicolumn{3}{|c|}{ (B) Escape speed $\left(\mathrm{cm} \mathrm{s}^{-1}\right)$} \\
\hline Stickleback & $8.58 \pm 4.31(32)$ & $7.05(1)$ \\
\hline Mysid & $12.79 \pm 4.23(44)$ & $6.82 \pm 2.02(8)$ \\
\hline
\end{tabular}

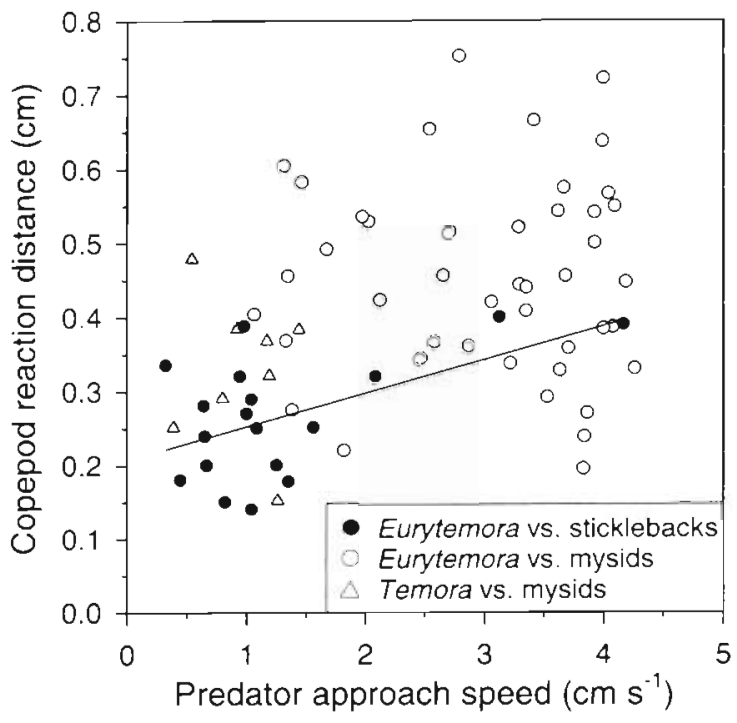

Fig. 7. Gasterosteus aculeatus and Neomysis integer vs Eurytemora affinis and Temora longicornis. Copepod reaction distances as a function of predator approach speed. Line: linear regression through stickleback-E. affinis data $\left[\mathrm{r}^{2}=0.29, F_{-}\right.$ ratio $=6.374, p=0.023$ )

Eurytemora affinis reacted to mysids from a significantly longer distance than to sticklebacks (means 0.45 and $0.24 \mathrm{~cm}$, respectively; Table $3 \mathrm{~A}$ ) (Student's $t$-test value $=6.99, \mathrm{p}<0.0001, \mathrm{df}=66$ ). Also, the escape speed of $E$. affinis was higher when escaping from mysids than when evading fish (12.79 vs $8.59 \mathrm{~cm} \mathrm{~s}^{-1}$; Table 3B). Temora longicornis did not react differently to the predators.

When escaping before a stickleback attacked, Eurytemora affinis performed short (mean length $0.81 \mathrm{~cm}$ ) sequential escapes, with the fish pursuing for up to $10 \mathrm{~s}$. When escaping during attack, E. affinis travelled a longer distance (mean $1.81 \mathrm{~cm}, \max .5 .85 \mathrm{~cm}$ ), and often used an irregularly shaped, zigzagging or spiralling path. This apparently confused the sticklebacks, because they were rarely able to relocate the escaped E. affinis. In contrast, Temora longicornis performed simpler, forward-darting escapes.

The reaction distance of Eurytemora affinis was positively correlated with stickleback approach speed (Fig. 7, black circles; Pearson $r=0.53, p=0.023, n=$ 18), but not with the approach speed of mysids (Fig. 7 . open circles; Pearson $\mathrm{r}<0.001, \mathrm{p}=0.999, \mathrm{n}=44$ ). The observations on the Temora longicornis-mysid interaction did not showed a consistent pattern (Fig. 7, grey triangles; Pearson $r=-0.139, p=0.743, n=8$ ). On the other hand, the approach speed of mysids (Fig. 8) was positively correlated with copepod escape speed ( $E$. affinis: Pearson $r=0.43, p=0.004, n=44 ; T$. longicor nis: Pearson $r=0.67, \mathrm{p}=0.069, \mathrm{n}=8$ ). 


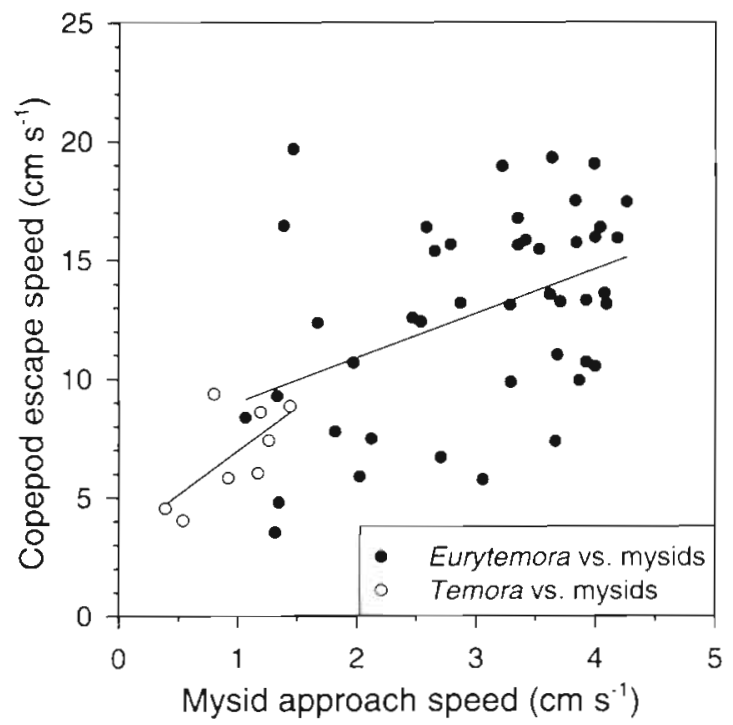

Fig. 8. Neomysis integer vs Eurytemora affinis and Temora longicornis. Escape speeds of E. affinis ( ) and T. longicornis (O), as a function of approach speed of mysids. Solid lines: linear regressions through the 2 data sets $\left(E\right.$. affinis: $\mathrm{r}^{2}=0.18, F-$ ratio $=9.397, \mathrm{p}=0.004 ; T$. longicornis: $\mathrm{r}^{2}=0.45, F$-ratio $=4.895$,

$$
p=0.069 \text { ) }
$$

\section{Experiments with artificial flow}

In the experiment with artificial flow, Eurytemora affinis were never captured when they were drawn towards the pipette for the first time. In 5 cases the copepods were, however, captured after a long series of jumps against the flow. Thus, $9 \%$ of the 56 interactions ended in a 'capture'. In contrast, the 'capture success' with Temora longicornis was $74 \%$ : in 23 cases out of 50 were $T$. longicornis sucked into the pipette without escape, whereas 14 interactions ended in capture after 1 or more escapes.

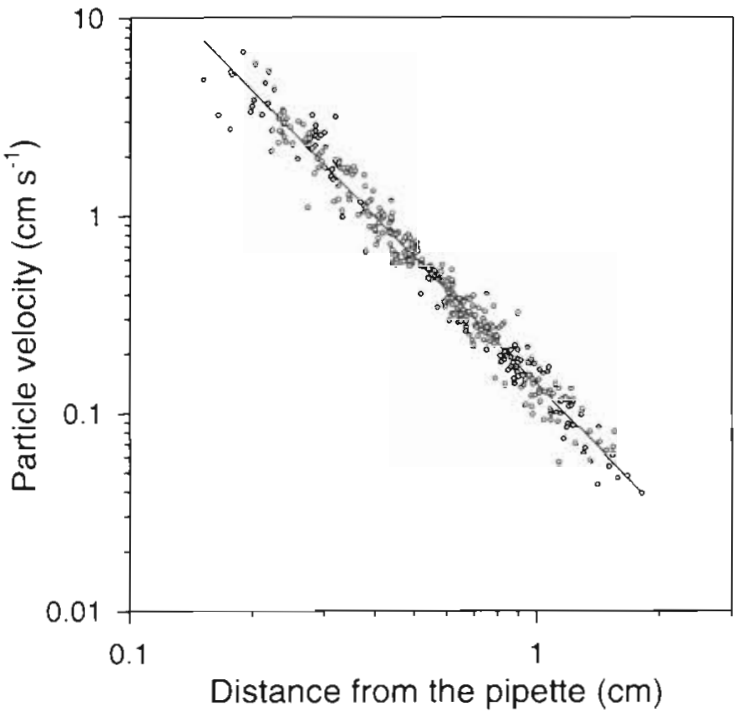

Fig. 9. Experiment with artificial flow. Velocities (v) of neutrally buoyant particles in relation to distance $(r)$ from the opening of the pipette. Regression equation of the line is $v=$ $0.139 r^{-2125}$; variation explained, $r^{2}=0.97$

Fig. 9 shows the relationship between fluid velocity $(v)$ and distance from the opening of the pipette $(r)$, determined by following the near-neutrally buoyant particles. This relationship was described by $v=$ $0.139 r^{-2125}$ (variation explained, $r^{2}=0.97$ ). Fig. 10 shows the escape locations of Eurytemora affinis and Temora longicornis in this flow field. Note that in this presentation the third dimension (second horizontal axis, y) was removed by folding all escape points onto the $x-z$ plane. The problem with this method is that it emphasises the number of observations farther away from the axis of the pipette, because they are integrated from a larger volume of water than those close to the axis of the pipette. However, this presentation
Fig. 10. Experiment with artificial flow. Escape locations of (A) Eurytemora affinis and (B) Temora longicornis relative to the pipette. The pipette is denoted by the shaded box; the opening of the pipette is at the origin of the coordinates. Note that the third dimension (second horizontal axis, $y$ ) has been removed by folding all escape points to the $x-z$ plane (see text for further discussion)
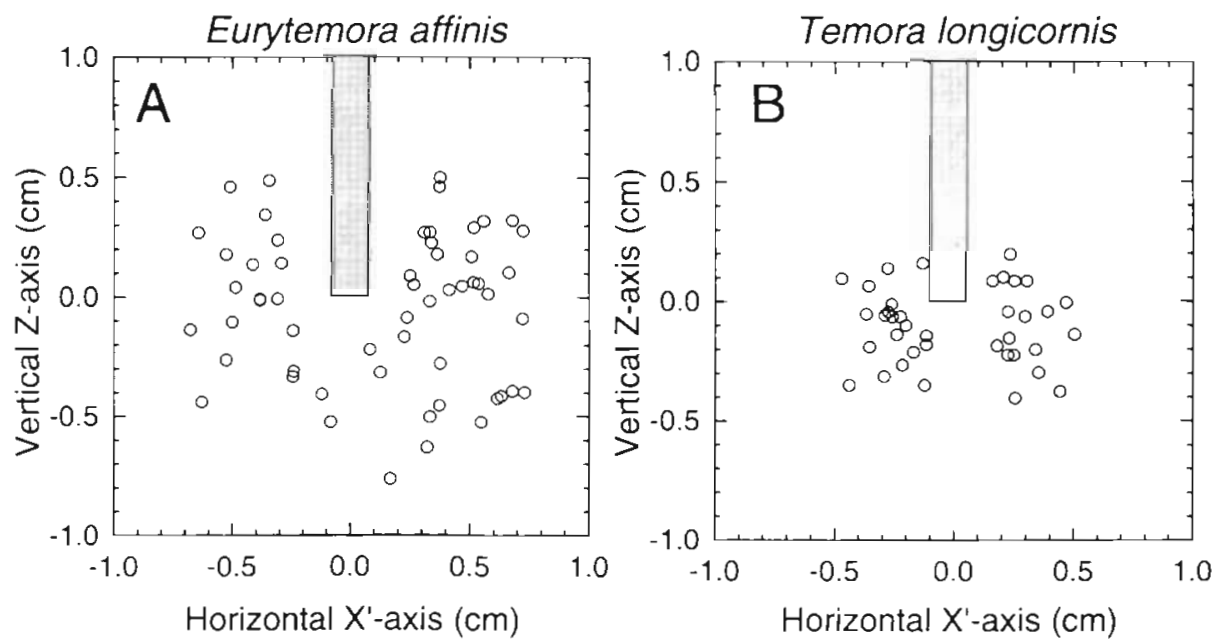
Table 4. Experiment with artificial flow. Copepod reaction distances from the tip of the pipette and escape speeds during the first $0.06 \mathrm{~s}$ of the escape. Data include observations from below the level of the pipette opening. $n=$ no. of observations

\begin{tabular}{|c|c|c|}
\hline \multirow[t]{2}{*}{ Variable } & \multicolumn{2}{|c|}{ Copepod species } \\
\hline & $\begin{array}{c}\text { Eurytemora } \\
\text { affinis } \\
\text { Mean } \pm \mathrm{SD}(\mathrm{n})\end{array}$ & $\begin{array}{c}\text { Temora } \\
\text { longicornis } \\
\text { Mean } \pm \text { SD (n) }\end{array}$ \\
\hline Reaction distance $(\mathrm{cm})$ & $0.53 \pm 0.20(28)$ & $0.35 \pm 0.11(29)$ \\
\hline Escape speed $\left(\mathrm{cm} \mathrm{s}^{-1}\right)$ & $5.51 \pm 2.51$ & $4.69 \pm 1.75(29)$ \\
\hline
\end{tabular}

correctly illustrates copepod reaction distances relative to the opening of the pipette. We note that $E$. affinis reacted to the pipette from a significantly larger distance than $T$. longicornis (means $0.53 \mathrm{~cm}$ and 0.35 $\mathrm{cm}$, respectively; Table 4) (Student's $t$-test value $=4.49$, $p<0.0001, \mathrm{df}=55$ ).

Because the flow velocity increases approximately with distance to the pipette squared (cf. Fig. 9), a relatively small difference between the reaction distances of copepods implies a large difference between their hydrodynamic sensitivities. We can estimate the threshold flow velocities and velocity gradients that elicit an escape in the copepods by inserting the observed mean reaction distances $(r)$ into the velocity equation, $v=0.139 r^{-2.125}$, and into the velocity gradient equation, $\partial v / \partial r=0.296 r^{-3.125}$ (obtained by differentiation of the velocity equation). Table 5 shows these thresholds calculated for the 2 copepod species. We note that, although the reaction distance of Temora longicornis was only $34 \%$ shorter than that of E. affinis, the average fluid velocity gradient that is needed to elicit an escape is 4 times higher in T. longicornis than in E. affinis (8.2 and $2.1 \mathrm{~s}^{-1}$, respectively).

Table 5. Experiment with artificial. flow. Reaction distances, $r$ $(\mathrm{cm})$, and estimates of thresholds for velocity, $v\left(\mathrm{~cm} \mathrm{~s}^{-1}\right)$, and for velocity gradient, $\partial v / \partial r\left(\mathrm{~s}^{-1}\right)$, that elicit an escape response in Eurytemora affinis and Temora Iongicornis (calculated for the average reaction distance, $r$ and for $r \pm$ standard deviation, SD)

\begin{tabular}{|lcr|}
\hline Reaction distance & $V$ & $\partial V / \partial r$ \\
\hline Eurytemora affinis & & \\
$r-\mathrm{SD}=0.33$ & 1.41 & 8.89 \\
$r \quad=0.53$ & 0.53 & 2.12 \\
$r+\mathrm{SD}=0.73$ & 0.27 & 0.80 \\
Temora longicornis & & \\
$r-\mathrm{SD}=0.24$ & 2.96 & 26.51 \\
$r \quad=0.35$ & 1.33 & 8.21 \\
$r+\mathrm{SD}=0.46$ & 0.75 & 3.51 \\
\hline
\end{tabular}

\section{DISCUSSION}

Our experiments showed that (1) the 2 copepod species had different susceptibilities to predation; (2) the reaction distance of one of the copepods (Eurytemora affinis) correlated with stickleback approach speed; and, consequently, (3) the capture success of the slowapproaching fish was higher than that of fish that approached their prey at a high speed. Furthermore, (4) both copepod species detected the mysids from a larger distance than they detected the sticklebacks, but (5) copepod reaction distance was not correlated with mysid approach speed. Below, we consider these findings in relation to hydromechanical signals generated by the predator and sensory abilities of the prey, and with respect to their behavioural modes.

\section{Hydrodynamic considerations}

The flow field created by the pipette resembles that directly in front of the approaching fish, in the sense that it is characterised solely by along-streamline velocity gradients. We therefore used the artificial flow to evaluate the magnitude of the threshold velocity gradient for the 2 copepod species. Ideally, the flow field generated by the pipette is characterised by velocity gradients that vary as a function of the distance to the pipette, while tangential velocity gradients are zero (see below, however). By noting the distance from the pipette at which the copepods escaped, threshold velocity gradients, $\gamma^{*}$, of ca 2 and $8 \mathrm{~s}^{-1}$ were estimated for Eurytemora affinis and Temora longicornis, respectively (Table 5). The estimated isolines of copepod reaction distance versus fish approach speed with these threshold sensitivities were depicted in Fig. 2. If we now plot the reaction and attack distances observed in the predator experiments as a function of fish approach speed, we note that the mean observations compare favourably with the model, albeit with large variation (cf. the symbols and SD bars in Fig. 2). For instance, the higher threshold gradient estimated for $T$. longicornis is consistent with the almost entire lack of escape responses observed with sticklebacks: the combination of mean approach speed $\left(0.90 \mathrm{~cm} \mathrm{~s}^{-1}\right)$ and attack distance $(0.11 \mathrm{~cm})$ in the successful attacks, and threshold gradient of $8.2 \mathrm{~s}^{-1}$ (Fig. 2, filled triangle) would suggest that all approaches are successful, as observed (with one exception). Likewise, the combination of the mean attack distance $(0.08 \mathrm{~cm})$ and threshold velocity gradient $\left(2.1 \mathrm{~s}^{-1}\right)$ for the stickleback-E. affinis combination would suggest that the fish should approach the copepod with a speed of $<0.53 \mathrm{~cm} \mathrm{~s}^{-1}$ in order not to be perceived. This agrees with the average approach speed of successful attacks observed, 
$0.48 \mathrm{~cm} \mathrm{~s}^{-1}$ (cf. Fig. 5). And, finally, the combination of mean approach speed in the interactions where the fish were perceived before attack $\left(1.29 \mathrm{~cm} \mathrm{~s}^{-1}\right)$ and a threshold gradient of $2.1 \mathrm{~s}^{-1}$ for the stickleback-E. affinis combination predicts a reaction distance $(R)$ of $0.18 \mathrm{~cm}$ for $E$. affinis. This is slightly less than actually observed $(0.24 \mathrm{~cm})$, but, due to the variability in the estimates of the threshold gradient, this is well within the standard error $\left(0.8\right.$ to $\left.8.9 \mathrm{~s}^{-1}\right)$ of the mean value estimated for E. affinis (cf. Table 5).

As noted above, we assume that the copepod perceives a hydrodynamic disturbance by the bending of extending setae. Such bending may occur if there is a velocity difference between the copepod and the ambient fluid. A velocity difference may occur by 2 mechanisms, one being proportional to acceleration of the fluid and the other being proportional to the velocity gradient. The first mechanism derives from the fact that a copepod has a density slightly higher than that of the ambient water. Its acceleration will therefore be somewhat less than that of the fluid. For a constant acceleration, the slip velocity $\left(\Delta w_{1}\right)$ due to this mechanism is simply $\Delta w_{1}=w_{\mathrm{s}} \cdot a_{1} / a_{\mathrm{g}}$, where $w_{\mathrm{s}}$ is the sinking velocity of the copepod, $a_{i}$ the acceleration of the fluid $(=v \cdot \partial v / \partial r)$, and $a_{q}$ the gravitational acceleration. Therefore, the strength of the signal generated by this mechanism is directly proportional to the acceleration of the fluid. The second mechanism is due to the fact that copepods have spatial dimensions. Within a velocity gradient, all parts of a rigid particle of extension $L$ (defined by copepod body length or the tips of the antenna) cannot travel with the same velocity as the fluid. If we assume that the midpoint of the copepod moves (and accelerates) with the fluid, there is a velocity difference between the midpoint and the front (or rear) end of the copepod. This velocity difference, $\Delta w_{2}$, can be estimated as $\Delta w_{2}=0.5 \cdot L \cdot \partial v / \partial r_{1}$ and the strength of the signal is therefore directly proportional to the velocity gradient. Which of these 2 processes, $\Delta w_{1}$ or $\Delta w_{2}$, dominates? We may estimate this by examining their ratio: $\Delta w_{1} / \Delta w_{2}=w_{4} \cdot v /\left(0.5 \cdot L \cdot a_{g}\right)$. By noting that, for the copepods considered here, the sinking velocity $w_{5}$ is $\sim 0.1 \mathrm{~cm} \mathrm{~s}^{-1}$ (e.g. Tiselius \& Jonsson 1990), $L \sim 0.1 \mathrm{~cm}$ and $a_{g} \sim 1000 \mathrm{~cm} \mathrm{~s}^{-2}$, it follows that $\Delta w_{1} / \Delta w_{2}=v / 500$. In other words, $\Delta w_{2}$ is larger than $\Delta w_{1}$ at all fluid velocities below $500 \mathrm{~cm} \mathrm{~s}^{-1}$. We can therefore conclude that the signal perceived by the copepad is directly proportional to the velocity gradient, as assumed in the model.

Our interpretation of the pipette experiments also assumes that the artificial flow field is characterised solely by along-streamline velocity gradients. However, due to the presence of a solid body in the flow (the pipette), the flow will be distorted, particularly along the sides of the pipette. Fields \& Yen (1996,
1997), using experiments similar to those presented here, observed more escapes on the sides of the pipette than in front of it, and argued that the copepods respond to 'shear' rather than to the along-streamline velocity gradients. However, as noted above, the graphical presentation of the escape events folded onto the $x-z$ plane under-represents escapes that take place in front of the pipette. Taking this into account, the escape positions observed by Fields \& Yen (1996. 1997) are actually evenly distributed around the pipette mouth. Furthermore, the magnitude and spatial distribution of 'shear', as defined and estimated by Fields \& Yen (velocity gradient perpendicular to the vertical direction estimated from video recordings of particle displacements), strongly depend on the orientation of the coordinate system to which the observations refer, as well as on the spatial separation distance used to estimate velocity gradients.

Our model must, however, be interpreted with caution since it is based on certain further assumptions, which may not be fully warranted: (1) the predator is spherical; (2) the calculated flow field refers to constant predator approach speed, while in fact the fish decelerates during approach; (3) the flow is assumed to be laminar, i.e. the Reynolds number is low. In fact, the Reynolds number approaches 10 and the assumption of creeping flow may be violated to some extent. Nevertheless, using independent estimates of threshold gradients from the pipette experiments, the model provided estimates of reaction distances and capture success that were of the correct order of magnitude.

\section{Predator foraging modes and prey sensory abilities}

Our model predicts that copepod reaction distance will shorten with decreasing approach velocity of the fish, but that, below a certain approach speed (at the intercept of the copepod's threshold isoline with the $x$ axis, Fig. 2), the copepod will not perceive the fish at all. This hyperbolic relationship between predator speed and copepod reaction distance thus conforms better with reality than the linear relationship depicted in Fig 7, which would predict copepods reacting to a perfectly still stickleback at a distance of $\sim 0.2 \mathrm{~cm}$. This implies that, when entering the perceptive zone of the copepod ( $-0.5 \mathrm{~cm}$ with Eurytemora affinis), the fish needs to keep its speed below ca $0.5 \mathrm{~cm} \mathrm{~s}^{-1}$, to be able to get within a strike distance $(-0.1 \mathrm{~cm})$ without inducing an escape. On the other hand, the model also predicts the copepod reaction distance to increase with the approach velocity of the fish. From the point of view of the predator this means that it can approach faster when it is farther away from the prey. Approaching at a constant low speed would be 'too cautious', 
since it would give more time for the prey to move and, in the case of schooling fish, would provide an opportunity for the other fish to snatch the prey. An optimal strategy for sticklebacks is therefore to approach at a declining speed that, at each distance, is just below the speed that elicits an escape in the copepod. The sticklebacks indeed seemed to use this strategy: they started the approach at a high initial speed, decelerated, and used a final approach speed that was close to the maximum allowable within the copepod perceptive zone. There was a lot of variation in the fine-tuning of this strategy, however, which gave the copepods a chance to detect the predator and evade.

In contrast, the model provided an inadequate description of the Neomysis integer-copepod interaction: the reaction distance of either Eurytemora affinis or Temora longicornis was not correlated with mysid approach speed (cf. Fig. 7). This may be due to the fact that a mysid swims with its 4 antenna spread to form a wide sensory apparatus, and propels itself forward with its thoracic appendages. This morphology coupled with the swimming mode probably produces a strong vibration that the mechanosensing prey are able to detect, but which is difficult to model. This was supported by the long reaction distance of $E$. affinis in response to mysids. It is possible that the hydrodynamic signal generated by a mysid is not so much related to the mysid swimming speed, but to some other factor, such as the appendage beat frequency.

We recognise that a 1.1 aquarium filled with filtered seawater hardly represents a natural environment for any of the experimental species. The initial prey concentrations were higher than normally occur in the study area (cf. Viitasalo 1992, Viitasalo et al. 1995). On the other hand, many copepod species show swarming behaviour, with densities reaching 500 to 2000 ind. $1^{-1}$ (Hamner \& Carleton 1979, Ueda et al. 1983), which suggests that predators may sometimes encounter our experimental prey densities (up to 200 ind. $1^{-1}$ ) in the field. Another problem of our experimental set-up was the small size of the aquarium, which was dictated by the filming equipment. Behaviour of copepods, mysids and fish may be disturhed close to the aquarium walls, and we therefore disregarded all interactions that took place $<1 \mathrm{~cm}$ from the walls. The sufficiency of the remaining $\sim 8 \mathrm{~cm}$ wide free space depends on the spatial dimensions of escapes and attacks. According to our measurements, copepods almost never escaped for longer than $2 \mathrm{~cm}$; sticklebacks detected prey from an average distance of $\sim 2 \mathrm{~cm}$, and attacked from $\sim 0.1 \mathrm{~cm}$ from the prey. Total attack duration was $\sim 0.06 \mathrm{~s}$, which means that the fish darted forward 0.2 to $0.4 \mathrm{~cm}$ during the attacks (with average attack speeds of $\sim 4$ to $6 \mathrm{~cm} \mathrm{~s}^{-1}$; cf. Table 2). Neither the copepods nor the sticklebacks were seen to hit aquarium walls during the filming. We therefore believe that the escape behaviour of copepods and the attack behaviour of sticklebacks were not much different from those in the field. In contrast, aquarium walls apparently disturbed Neomysis integer; they were occasionally seen to stumble against the walls while cruising. Darkness may also have been a sub-optimal feeding condition for $N$. integer. Higher feeding rates in well-lit conditions compared to darkness have previously been observed in Mysis relicta (Ramcharan \& Sprules 1986). On the other hand, our observations agree with other studies which have shown that $N$. integer is not an efficient feeder of adult copepods (Aaser et al. 1995, Uitto et al. 1995, A. Uitto pers. comm.).

The predation risk of the copepods studied appeared to depend more on their mechanosensory capabilities prior to attack than on the escaping performance during attack. From both predator and pipette experiments it became obvious that Eurytemora atfinis is more sensitive to predator-generated flows than Temora longicornis. The 4 times higher velocity gradient threshold estimated for $T$. longicornis explains their poor escape success with sticklebacks. This difference between the sensitivities of the 2 copepod species may be a consequence of their different feeding strategies. Both species are omnivorous (Schnack 1982, Yule \& Crisp 1983, Revis et al. 1991, Kleppel 1993, van Duren \& Videler 1995), but observations on their feeding behaviour suggest that $T$. longicornis is relatively more confined to stationary suspension feeding than E. affinis (Berk et al. 1977, Tiselius \& Jonsson 1990). E. affinis may therefore possess more sensitive hydrodynamic sensors, which enable this species to detect approaching predators from a longer distance. On the other hand, it has been shown that visual predators (Baltic herring) actively select ovigerous $E$. affinis as food (Sandström 1980, Flinkman et al. 1992). This suggests that there is a strong selection pressure towards evolving efficient escape responses in $E$. affinis females.

\section{Conclusion}

Our study confirmed that there are important differences between escape capabilities of copepod species, and that the swimming mode and the approaching skill of predators are important for their foraging success. This was highlighted by the low capture rates of sticklebacks that approached their. prey too fast, and by the poor feeding success of the 'noisily' swimming mysids. We do not know if the predators showed a true preference towards either of the prey species, but we conclude that the lower escape capability of Temora longicornis will (in the case of a non-selective preda- 
tor) result in 'apparent prey selection' towards this copepod species. The good match between the model and experimental observations was also encouraging. By using 'Occam's razor', we suggest that it is the simplest of the possible hydrodynamic cues, i.e. the velocity gradient, that elicits the escape response in copepods. This implies that, by ranking the escape performance of various zooplankton species by simple artificial flow experiments, we can predict their vulnerabilities to predation by small fish. If we compare these results with stomach content analyses of predators, we can assess which prey species are truly selected, and which are common feed just because of their poor escape capabilities. In contrast, our hydrodynamic model did not provide an adequate description of the interaction between copepods and Neomysis integer, and the hydrodynamic background of mysid foraging remains to be solved.

Acknowledgements. This study was financed by the Academy of Finland, the Walter and Andree de Nottbeck Foundation and Danish Institute for Fisheries Research. T.K. was supported by a grant, \#9502/63, from the Danish Natural Sciences Research Council. The experiments were conducted at Tvärminne Zoological Station, University of Helsinki. Peter Tiselius and Magnus Lindström kindly provided some of the filming equipment. We thank Brian MacKenzie and Ilppo Vuorinen for thoughtful comments on the manuscript.

\section{LITERATURE CITED}

Aaser HF, Jeppesen E, Sondergaard M (1995) Seasonal dynamics of the mysid Neomysis integer and its predation on the copepod Eurytemora affinis in a shallow hypertrophic brackish lake. Mar Ecol Prog Ser 127:47-56

Berg HC (1993) Random walks in biology. Princeton University Press, Princeton, NJ

Berk SG, Brownlee DC, Heinle DR, Kling HJ, Colwell RR (1977) Ciliates as a food source for marine planktonic copepods. Microb Ecol 4:27-40

Beukema JJ (1968) Predation by the three-spined stickleback (Gasterosteus aculeatus L.): the influence of hunger and experience. Behaviour 31:1-126

Brooks JL, Dodson SI (1965) Predation, body size, and composition of plankton. Science 150:28-35

Buskey EJ (1994) Factors affecting feeding selectivity of visual predators on the copepod Acartia tonsa: locomotion, visibility and escape responses. Hydrobiologia 292/293: $447-453$

Cooper SD, Goldman CR (1980) Opossum shrimp (Mysis relicta) predation on zooplankton. Can J Fish Aquat Sci 37:909-919

Coughlin DJ, Strickler JR, Sanderson B (1992) Swimming and search behaviour in clownfish, Amphiprion perideraion, larvae. Anim Behav 44:427-440

Drenner RW, McComas SR (1980) The roles of zooplankter escape ability and fish size selectivity in the selective feeding and impact of planktivorous fish. In: Kerfoot WC (ed) Evolution and ecology of zooplankton communities, University Press of New England, Hanover, NH, p 587-593

Drenner RW, Strickler JR, O'Brien WJ (1978) Capture probability: the role of zooplankter escape in the selective feed- ing of planktivorous fish. J Fish Res Bd Can 35:1370-1373

Drost MR (1987) Relation between aiming and catch success in larval fishes. Can J Fish Aquat Sci 44:304-315

Drost MR, Osse JWM, Muller M (1988) Prey capture by fish larvae, water flow patterns and the effect of escape movements of prey. Neth J Zool 38:23-45

Fields DM, Yen $J$ (1996) The escape behavior of Pleuromamma xiphias in response to a quantifiable fluid mechanical disturbance. Mar Freshw Behav Physiol 27. $323-340$

Fields DM, Yen J (1997) Implications of the feeding current structure of Euchaeta nimana, a carnivorous pelagic copepod, on the spatial orientation of their prey. J Plankton Res 19:79-95

Fleminger A (1973) Pattern, number, variability and taxonomic significance of integumental organs (sensilla and glandular pores) in the genus Eucalanus (Copepoda, Calanoida). Fish Bull US 71:965-1010

Flinkman J, Vuorinen I, Aro E (1992) Planktivorous Baltic herring (Clupea harengus) prey selectively on reproducing copepods and cladocerans. Can J Fish Aquat Sci 49:73-77

Flinkman J, Aro E, Vuorinen I, Viitasalo M (1998) Changes in northern Baltic zooplankton and herring nutrition from 1980s to 1990s: top-down and bottom-up processes at work. Mar Ecol Prog Ser 165:127-136

Gardner MB (1981) Mechanisms of size selectivity by planktivorous fish: a test of hypotheses. Ecology 62:571-578

Gerritsen J, Strickler JR (1977) Encounter probabilities and community structure in zooplankton: a mathematical model. J Fish Res Bd Can 34:73-82

Gilbert JJ, Kirk KL (1988) Escape response of the rotifer Keratella: description, stimulation, fluid dynamics, and ecological significance. Limnol Oceanogr 33:1440-1450

Gill CW (1985) The response of a restrained copepod to tactile stimulation. Mar Ecol Prog Ser 21:121-125

Greene CG (1986) Patterns of prey selection: implications of predator foraging tactics. Am Nat 128:824-839

Grossnickle NE (1982) Feeding habits of Mysis relicta-an overview. Hydrobiologia 93:101-107

Hamner WM, Carleton JH (1979) Copepod swarms: attributes and role in coral reef ecosystems. Limnol Oceanogr 24 $1-14$

Hangelin C, Vuorinen I (1988) Food selection in juvenile three-spined sticklebacks studied in relation to size, abundance and biomass of prey. Hydrobiologia 157:169-177

Hansson S, Larsson U, Johansson S (1990) Selective predation by herring and mysids, and zooplank ton community structure in a Baltic Sea coastal area. J Plankton Res 12 : $1099-1116$

Haury LR, Kenyon DE, Brooks JR (1980) Experimental evaluation of the avoidance reaction of Calanus finmarchicus. J Plankton Res 2:187-202

Holling CS (1959) The components of predation as revealed by a study of small-mammal predation of the European pine sawfly. Can Entomol 91:293-320

Irvine $\mathrm{K}$, Moss $\mathrm{B}$, Bales $\mathrm{M}$, Snook D (1993) The changing ecosystem of a shallow, brackish lake, Hickling Broad, Norfolk, U.K. 1. Trophic relationships with special reference to the role of Neomysis integer. Freshw Biol 29: $119-139$

Janssen J (1976) Selectivity of an artificial filter feeder and suction feeders on calanoid copepods. Am Midland Nat 95:491-493

Kerfoot WC (1978) Combat between predatory copepods and their prey: Cyclops, Epischura, and Bosmina. Limnol Oceanogr 23:1089-1102

Kils $U$ (1992) The ecoSCOPE and dynIMAGE: microscale 
tools for in situ studies of predator-prey interactions. Arch Hydrobiol Bein Ergebn Limnol 36:83-96

Kiorboe T, Visser AW (1999) Predator and prey perception distances in zooplankton due to hydromechanical signals. Mar Ecol Prog Ser (in press)

Kirk KL, Gilbert JJ (1988) Escape behavior of Polyarthra in response to artificial flow stimuli. Bull Mar Sci 43:551-560

Kleppel GS (1993) On the diets of calanoid copepods. Mar Ecol Prog Ser 99:183-195

Landry MR (1978) Predatory feeding behavior of a marine copepod, Labidocera trispinosa. Limnol Oceanogr 23: $1103-1113$

Leinikki J (1995) The diet of three-spined stickleback in the Gulf of Bothnia during its open water phase. Aqua Fennica $25: 71-75$

Mauchline J (1980) The biology of mysids and euphausiids Adv Mar Biol 18:1-677

Mohammadian MA. Hansson S, De Stasio BT (1997) Are marine planktonic invertebrates food limited? The functional response of Mysis mixta (Crustacea, Mysidacea) in the Baltic Sea. Mar Ecol Prog Ser 150:113-119

Nordström H (1997) Rantavyöhykkeen halkoisjalkaäyriäisten (Mysidacea) ravinnonkàyttö Itämeressä. MSc thesis, University of Helsinki, p 1-57

O'Brien WJ, Slade NA, Vinyard GL (1976) Apparent size as the determinant of prey selection by bluegill. sunfish (Lepomis macrochirus). Ecology 57:1304-1310

O'Brien WJ, Evans BI, Browman HI (1989) Flexible search tactics and efficient foraging in saltatory searching animals. Oecologia 80:100 110

O'Brien WJ, Browman HI, Evans BI (1990) Search strategies of foraging animals. Am Scient 78:152-160

Pastorok RA (1981) Prey vulnerability and size selection by Chaoborus larvae. Ecology 62:1311-1324

Rajasilta M (1980) Food consumption of three-spined stickleback (Gasterosteus aculeatus L.). Annl Zool Fenn 17 $123-126$

Ramcharan CW, Sprules WG (1986) Visual predation in Mysis relicta Lovén. Limnol Oceanogr 31:414-420

Revis N, Castel J, Tackx MLM (1991) Some reflections on the structure of the mandible plate of Eurytemora affinis (Copepoda, Calanoida). Hydrobiol Bull 25:45-50

Rudstam LG, Hansson S, Johansson S, Larsson U (1992) Dynamics of planktivory in a coastal area of the northern Baltic Sea. Mar Ecol Prog Ser 80:159-173

Sandström $O$ (1980) Selective feeding by Baltic herring Hydrobiologia 69:199-207

Schnack SB (1982) The structure of the mouth parts of copepods in Kiel Bay. Meeresforschung Rep Mar Res 29 $89-101$

Siegfried CA, Kopache ME (1980) Feeding of Neomysis mercedis (Holmes). Biol Bull 159:193-205

Singarajah KV (1969) Escape reactions of zooplankton: the avoidance of a pursuing siphon tube. J Exp Mar Biol Ecol $3: 171-178$

Singarajah KV (1975) Escape reactions of zooplankton: effects of light and turbulence. J Mar. Biol Assoc UK 55.627-639

Strickler. JR (1975) Intra- and interspecific information flow among planktonic copepods: receptors. Verh Int Verein Limnol 19:2951-2958

Strickler JR, Bal AK (1973) Setae of the first antennae of the copepod Cyclops scutifer (Sars): their structure and importance. Proc Natl Acad Sci USA 70:2656-2659

Szlauer L (1964) Reaction of Daphnia pulex de Geer to the approach of different objects. Pol Arch Hydrobiol 12: $5-16$

Szlauer L (1965) The refuge ability of plancion anmals before models of plancton-eating animals. Pol Arch Hydrobiol 13: $89-95$

Thorman S, Wiederholm AM (1986) Food, habitat and time niches in a coastal fish species assemblage in a brackishwater Bay in the Bothnian Sea, Sweden. J Exp Mar Biol Ecol 95:67-86

Tiselius P, Jonsson PR (1990) Foraging behaviour of six calanoid copepods: observations and hydrodynamical analysis. Mar Ecol Prog Ser 66:23-33

Tiselius P, Jonsson PR, Verity PG (1993) A model evaluation of the impact of food patchiness on foraging strategy and predation risk in zooplankton. Bull Mar Sci 53:247-264

Ueda H, Kuwahara A, Tanaka M, Azeta M (1983) Underwater observations on conepod swarms in temperate and subtropical waters. Mar Ecol Prog Ser 11:165-171

Uitto A. Kaitala S, Kuosa H, Pajuniemi R (1995) Effect of nutrient addition and predation of mysid shrimp (Neomysis integer) on a plankton community in a short-term enclosure experiment in the northern Baltic. Aqua Fenn 25: $23-31$

van Duren LA, Videler JJ (1995) Swimming behaviour of developmental stages of the calanoid copepod Temora longicornis at different food concentrations. Mar Ecol Prog Ser 126:153-161

Viitasalo M (1992) Mesozooplankton of the Gulf of Finland and northern Baltic Proper - a review of monitoring data Ophelia 35:147-1.68

Viitasalo M. Rautio M (1998) Zooplanktivory by Praunus flexuosus (Crustacea: Mysidacea): functional responses and prey selection in relation to prey escape responses. Mar Ecol Prog Ser 174:77-87

Viitasalo M, Vuorinen I, Saesmaa S (1995) Mesozooplankton dynamics in the northern Baltic Sea: implications of variations in hydrography and climate. J Plankton Res 17 . $1857-1.878$

Williamson CE (1980) The predatory behaviour of Mesocyclops edax: predator preferences, prey defenses, and starvation-induced changes. Limnol Oceanogr 25:903-909

Yen J, Fields DM (1992) Escape responses of Acartia hudsonica (Copenoda) nauplii from the flow field of Temora longiiornis (Copepoda). Arch Hydrobiol Berh Ergebn Limnol 36:123-134

Yen J, Strickler JR (1996) Advertisement and concealment in the plankton: what makes a copepod hydrodynamically conspicuous? Invertebr Biol 1.15:191-205

Yen J, Lenz PH. Gassie DV, Hartline DK (1992) Mechanoreception in marine copepods; electrophysiological studies on the first antennae. J Plankton Res 14:495-512

Yule AB, Crisp DJ (1983) A study of feeding behaviour in Temora longicornis (Müller) (Crustacea: Copepoda). J Exp Mar Biol Ecol 71:271-282

Zaret TM (1972) Predators, invisible prey, and the nature of polymorphism in the Cladocera (class Crustaced). Limnol Oceanogr 17:171-184

Zaret TM (1980) The effect of prey motion on planktivore choice. In: Kerfoot WC (ed) Evolution and ecology of zooplankton communities. University Press of New England, Hanover, NH, p 594-603

Zaret TM, Kerfoot C (1975) Fish predation un Bosmina longirostris: body-size selection versus visibility selection Ecology 56:232-237

Submitted: June 19, 1998; Accepted: September 9, 1998 Proofs received from duthor(s): November 25, 1998 